\title{
Agenda for Chemometricians
}

It is most appropriate that the proceedings of this conference are going to be dedicated to the memory of Jack Youden. He was interested in many of the topics that are being considered at this conference, for example, interlaboratory comparisons, calibration, analytical methods, and measurement errors-both systematic and random. He was indeed a pioneering chemometrician, before the name existed. He was also interested in explaining to chemists, chemical engineers, and others how they could benefit by using statistical methods.

I'm sure Youden would have been pleased with this conference, which provides a forum for chemists, statisticians, and others interested in chemometrics to discuss research of mutual interest. He also might have observed that chemometrics as a field has reached a level of maturity that warrants consideration of questions related to spreading the word to others, to non-chemometricians, so that they could take advantage of the techniques that are now available. In other words, perhaps chemometrics as discipline has reached a sufficiently advanced stage of research and development that questions of production should now be addressed. What are our most useful products? Who are out customers? Which products would they find most valuable? What are the obstacles that prevent these customers from using these products now? How can these obstacles be overcome? What are the most important things that can be done in the next three years to reach new customers? What should the agenda be for chemometricians in the next few years?

There are two ways to learn. One is to listen, as in a lecture. The other is to engage in a dialogue, as in a conversation. The first way is passive. The second is active. Let's try the second way to learn from one another how we might answer these questions.

[Participants at this point wrote out answers to these questions, discussed them, and voted on them. The top vote-getters for the most important things that can be done in the next three years to reach new customers were the following, listed in order of decreasing number votes:

1. Organize joint conferences with chemists.

2. Write textbooks on chemometrics.

3. Conduct workshops and teach short courses.

4. Write user-friendly software.

5. Teach chemometrics to graduate students. 
6. Write tutorial, expository, and review articles.

7. Undertake joint research projects with chemists.

8. Publicize success stories.

9. Teach chemometrics to undergraduate students.

10. Communicate with management.

11. Hire professionals to help with a public relations effort.

12. Teach chemometrics to high school students.]

I recommend that we take action on the basis of this list. Let me now make a few observations in closing. I would like to suggest a different starting point for statistics courses, Let us represent the relationship between an observed response $\mathrm{y}$ and variables $x_{1}, x_{2}, \ldots$ as

$$
y=f\left(x_{1}, x_{2}, x_{3}, x_{4}, x_{5}, \ldots, x_{126} \ldots\right) .
$$

Many, many, many variables affect $y$. It is the fluctuation of these variables that gives us different answers when we repeat an experiment two or more times under "identical conditions." We are often interested in creating a mathematical equation (model) that involves a subset of the variables. For purposes of illustration, suppose this subset is $\left(x_{1}, x_{2}\right)$. We can then write

$$
y=f\left(x_{1}, x_{2}\right)+g\left(x_{1}, x_{2}, x_{3}, x_{4}, x_{5}, \ldots, x_{126}, \ldots\right) .
$$

Note that the $\mathrm{g}$ function includes $x_{1}$ and $x_{2}$ (because of lack of fit of the model) as well as all the other $x$ 's. Lack of fit occurs, for example, because the model $\mathrm{f}$ may be taken to be linear in $x_{1}$ and $x_{2}$ but the actual relationship may be nonlinear in $x_{1}$ and $x_{2}$. The function $g$ is most often called experimental error, and it is almost as often endowed by writers with an abundance of desirable and well-known properties. They call it a random variable. A sequence of these experimental errors, they frequently say, can be assumed to be independent, identically distributed according to a Normal distribution with a zero mean and constant variance. I believe that statisticians too readily make this assumption and others like it. Sometimes such an assumption makes sense, sometimes not. We should be more careful on this point.

An adequate model is a function that will turn data into white noise, as George Box has said. An analogy that I find useful involves a process for separating gold particles from a slurry. If the process is fully efficient, the waste stream will contain no gold. It is therefore prudent to check the waste stream to see if it contains any gold. Likewise in creating and fitting models, it makes sense to examine residuals to see if they contain any information. The data contain information (that's the gold we want to get), and a good model will extract all the information in those data. Hence the residuals will be manifestations of white noise, an informationless sequence of values.

Chemists and chemical engineers could benefit from knowing more about variance components, statistical graphics, and quality control techniques (including Shewhart and cumulative sum charts). But, above all, I think they would find statistical experimental designs to be the most useful thing of all that chemometricians have to offer. Such designs provide a practical means for increasing research efficiency, which might be defined as the amount of information one obtains per dollar spent.

The damage done by poor experimental design is irreparable. A poor design results in data that contain little information. Consequently, no matter how thorough, how clever, or how sophisticated the subsequent analysis is, little information can be extracted. A good design, for the same expenditure of time, money, and other resources, results in data rich in information. A fruitful analysis is then possible. (Note that analysis is defined as trying to extract all the useful information in the data.)

Two-level factorial and fractional factorial designs can be extremely useful for chemists, chemical engineers, and others who do similar work. One of the best ways for a student to learn about such designs is to set one up, get the data, analyze them, and interpret the results. For a number of years $I$ have had students in our experimental design course undertake such projects. 
The main piece of advice I give them is to work on something they care about, something they are really interested in.

Toward the end of an introductory one-semester undergraduate course in statistics, for example, one student said that he was a pilot and that, ever since he started to fly, he had asked instructors and other pilots what he should do if the engine failed on takeoff. He had been told by several people that he should bank the plane, go into a $180^{\circ}$ turn, and land on the runway from which he took off. Unfortunately, many different ways of doing this maneuver had been suggested. He successfully organized and executed a replicated $2^{3}$ factorial design with three variables: bank angle, flap angle, and speed. He measured the loss in altitude. He started each test at 1000 feet instead of ground level. The experiment was a success. He learned which combination of factors he should use for his plane, and he discovered the minimum altitude for attempting such a maneuver.

Factorial designs can be understood and run with profit by graduate, undergraduate, senior high school, and junior high school students. Maybe younger students can use them, too. Students can study the baking of cakes, the riding of bicycles, the making of chemicals, the growing of plants, and the swinging of pendulums. Dalia Sredni, when she was a seventh grader, for instance, studied the effects of changing oven temperature, baking time, and the amount of baking soda when making a cake. Students should be told about factorial designs early so that they can study systems that depend on many variables and learn how they work. Using such designs they can discover interesting things, have fun, and be surprised. Our students deserve more of these pleasures. I have included a list of 101 experiments that have been done by students at Wisconsin, to indicate the variety of things that is possible.

I would like to end by congratulating the conference organizers for the excellent job they have done. It is clear that they have worked hard to make things enjoyable and rewarding for those of us who have been fortunate enough to participate.

\section{William G. Hunter}

\section{Professor of Statistics and Industrial Engineering Director of Center for Quality and Productivity Improvement University of Wisconsin-Madison}

Table 1. List of some studies done by students in an experimental design course at the University of Wisconsin-Madison. variables responses

\begin{tabular}{l|l}
\hline $\begin{array}{l}\text { 1. seat height (26, } 30 \text { inches), generator (off, on), tire pressure (40,55 psi) } \\
\begin{array}{l}\text { 2. brand of popcorn (ordinary, gourmet), size of batch }(1 / 3,2 / 3 \text { cup), popcorn to oil } \\
\text { ratio (low, high) }\end{array}\end{array}$ & $\begin{array}{l}\text { time to complete fixed course on bicycle and pulse } \\
\text { rate at finish }\end{array}$ \\
\hline 3. amount of yeast, amount of sugar, liquid (milk, water), rise temperature, rise time & quality of bread, especially the total rise \\
\hline 4. number of pills, amount of cough syrup, use of vaporizer & how well twins, who had colds, slept during the night \\
\hline 5. speed of film, light (normal, diffused), shutter speed & $\begin{array}{l}\text { quality of slides made close up with flash attachment } \\
\text { on camera }\end{array}$ \\
\hline 6. hours of illumination, water temperature, specific gravity of water & growth rate of algae in salt water aquarium \\
\hline 7. temperature, amount of sugar, food prior to drink (water, salted popcorn) & taste of Koolaid \\
\hline 8. direction in which radio is facing, antenna angle, antenna slant & $\begin{array}{l}\text { strength of radio singal from particular AM station in } \\
\text { Chicago }\end{array}$ \\
\hline 9. blending speed, amount of water, temperature of water, soaking time before blend- \\
ing & blending time for soy beans \\
\hline
\end{tabular}


Table 1. continued

variables

responses

10. charge time, digits fixed, number of calculations performed

11. clothes dryer (A, B), temperature setting, load

12. pan (aluminum, iron), bumer on store, cover for pan (no, yes)

13. aspirin buffered? (no, yes), dose, water temperature

14. amount of milk powder added to milk, heating temperature, incubation temperature

15. pack on back (no, yes), footwear (tennis shoes, boots), run $(7,14$ flights of steps)

16. width to height ratio of sheet of balsa wood, slant angle, dihedral angle, weight added, thickness of wood

17. Level of coffee in cup, devices (nothing, spoon placed across top of cup facing up), speed of walking

18. type of stitch, yam guage, needle size

19. type of drink (beer, rum), number of drinks, rate of drinking, hours after last meal

20. size of order, time of day, sex of server

21. brand of gasoline, driving speed, temperature

22. stamp (first class, air mail), zip code (used, not used), time of day when letter mailed

23. side of face (left, right), beard history (shaved once in two years-sideburns, shaved over 600 times in (wo years-just below sideburns)

24. eyes used (both, right), location of observer, distance

25. distance to target, guns $(A, B)$, powders $(C, D)$

26. oven temperature, length of heating, amount of water

27. strength of developer, temperature, degree of agitation

28. brand of rubber band, size, temperature

29. viscosity of oil, type of pick-up shoes, number of teeth in gear

30. type of tire, brand of gas, driver (A, B)

31. temperature, stirring rate, amount of solvent

32. amounts of cooking wine, oyster sauce, sesame oil

33. type of surface, object (slide rule, ruler, silver dollar), pushed? (no, yes)

34. ambient temperature, choke setting, number of charges

35. temperature, location in oven, biscuits covered while baking? (no, yes)

36. temperature of water, amount of grease, amount of water conditioner

37. person putting daughter to bed (mother, father), bed time, place (home, grandparents)

38. amount of light in room, type of music played, volume

39. amounts of added Turkish, Latakia, and Perique tobaccos

40. temperature, humidity, rock salt

41. number of cards deait at one time, position of picker relative to the dealer

42. marijuana (no, yes), tequilla (no, yes), sauna (no, yes) operation time for pockel calculator

time until dryer stops

time to boil water

hours of relief from migraine headache

taste comparison of homemade yogurt and commercial brand

time required to run up steps and heartbeat at top

length of flight of model airplane

how much coffee spilled while walking

cost of knitting scarf, dollars per square foot

time to get steel ball through a maze

cost of onder of french fries, in cents per ounce

gas mileage for car

number of days required for letter to be delivered to another city

length of whiskers 3 days after shaving

number of times (out of 15 ) that correct gender of passerby was determined by experimenter with poor ejesight wearing no glasses

number of shot that penetrated a one foot diameter circle on the target

height of cake

densicy of photographic film

length of rubber band before it broke

speed of H.O. scale slot racers

time for car to cover one-quarter mile

time to dissolve table salt

taste of stewed chicken

angle necessary to make object slide

number of kicks necessary to start motorcycle

time to bake biscuits

quantity of suds produced in kitchen blender

toys child chose to sleep with

correct answers on simple arithmetic test, time required to complete test, words remembered (from list of (5)

bite, smoking characteristics, aroma, and taste of tobacco mixture

time to melt ice

points in games of sheepshead, a card game

pleasure experienced in subsequent sexual intercourse 
Table 1. continued

43. amounts of flour, eggs, milk

44. brand of suntan lotion, altitude, skier

45. amount of sleep the night before, substantial exercise during the day? (no, yes), eat right before going to bed? (no, yes)

46. brand of tape deck used for playing music, bass level, treble level, synthesizer? (no, yes)

47. Type of filter paper, beverage to be filtered, volume of beverage

48. type of ski, temperature, type of wax

49. ambient temperature for dough when rising, amount of vegetable oil, number of onions

50. amount of fertilizer, location of seeds ( $3 \times 3$ Latin square)

51. speed of kitchen blender, batch size of malt, blending time

52. soft drink (A, B), container (can, bottle), sugar free? (no, yes)

53. child's weight $(13,22$ pounds $)$, spring tension $(4,8$ cranks), swing orientation (level, tilted)

54. orientation of football, kick (ordinary, soccer style), steps taken before kick, shoe (soft, hard)

55. weight of bowling ball, spin, bowling lane (A, B)

56. distance from basket, type of shot, location on floor

57. temperature, position of glass when pouring soft drink, amount of sugar added

58. brand of epoxy glue, ratio of hardener to resin, thickness of application, smoothness of surface, curing time

59. amount of plant hormone, water (direct from tap, stood out for 24 hours), window in which plant was put

60. amount of detergent ( $1 / 4,1 / 2$ cup), bleach (none, 1 cup), fabric softener (not used, used)

61. skin thickness, water temperature, amount of salt

62. appearance (with and without a crutch), location, time

63. frequency of watering plants, use of plant food (no, yes), temperature of water

64. plunger A up (slow, fast), plunger A down (slow, fast), plunger B up (slow, fast) plunger B down (slow, fast)

65. temperature of gas chromatograph column, tube type $(\mathrm{U}, \mathrm{J})$, voltage

66. temperature, gas pressure, welding speed

67. concentration of lysozyme, $\mathrm{pH}$, ionic strength, temperature

68. anhydrous barium peroxide powder, sulfur, charcoal dust

69. air velocity, air temperature, rice bed depth

70. concentration of lactose crystal, crystal size, rate of agitation

71. positions of coating chamber, distribution plate, and lower chamber

72. proportional band, manual reset, regulator pressure

73. chloride concentration, phase ratio, total amine concentration, amount of preservative added taste of pancakes, consensus of group of four living together

time to get sunburned

soundness of sleep, average reading from 5 persons

clearness and quality of sound, and absence of noise

time to filter

time to go down ski slope

four quality characteristics of pizza

time for seeds to germinate

quality of ground malt for brewing beer

taste of drink from paper cup

number of swings and duration of these swings obtained from an automatic infant swing

distance football was kicked

bowling pins knocked down

number of shots made (out of 10 ) with basketball

amount of foam produced when pouring soft drink into glass

strength of bond between two strips of aluminum

root lengths of cuttings from purple passion vine after 21 days

ability to remove oil and grape juice stains

time to cook chinese meat dumpling

time to get a ride hitchhiking and number of cars that passed before getting a ride

growth rate of house plants

reproducibility of automatic dilutor, optical density

readings made with spectrophotometer

size of unwanted droplet

strength of polypropylene weld, manual operation

rate of chemical reaction

length of time fuse powder burned and the evenness of burning

time to dry wild rice

spreadability of caramel candy

number of particles caught in a fluidized bed collector

sensitivity of a pneumatic valve control system for a

heat exchanger

degree of separation of zinc from copper accom-

plished by extraction 
Table 1. continued

variables

responses

\begin{tabular}{l} 
74. temperature, nitrate concentration, amount of preservative added \\
$\begin{array}{l}\text { 75. solar radiation collector size, ratio of storage capacity to collector size, extent of } \\
\text { short-term intermittency of radiation, average daily radiation on three successive } \\
\text { days }\end{array}$ \\
\hline $76 . \mathrm{pH}$, dissolved oxygen content of water, temperature \\
\hline 77. amount of sulfuric acid, tine of shaking milk-acid mixture, time of final tempering \\
\hline 78. mode (batcin, time-sharing), job size, system utilization (low, high) \\
\hline 79. flow rate of carrier gas, polarity of stationary liquid phase, temperature
\end{tabular}

80. $\mathrm{pH}$ of assay buffer, incubation time. concentration of binder

81. aluminum, boron, cooling time

82. magnification, read out system (micrometer, electronic), stage light

83. riser height, mold hardness, carbon equivalent

84. amperage, contact tube height, travel speed, edge preparation

85. time, amount of magnesium oxide, amount of alloy

86. $\mathrm{pH}$, depth, time

87. deodorant, concentration of chemical, incubation time

88. temperature variation, concentration of cupric sulfate concentration of sulfuric acid

89. air flow, diameter of bead, heat shield (no, yes)

90. voltage. warm-up procedure, bulb age

91. pressure, amount of ferric chloride added, amount of lime added

92. longitudinal feed rate, transverse feed rate, depth of cut

93. time between preparation of sample and refluxing, reflux time, time between end of reflux and start of titrating

94. speed of rotation, thrust load, method of lubrication

95. type of activated carbon, amount of carbon, $\mathrm{pH}$

96. amounts of nickel, manganese, carbon

97. form (broth, gravy), added broth (no, yes), added fat (no, yes), type of meat (lamb, beef)

98. well $(A, B)$, depth of probe, method of analysis (peak height, planimeter)

99. paste (A, B), preparation of skin (no, yes), site (sternum, forearm)

100. lime dosage, time of flocculation, mixing speed

101. temperature difference between surface and bottom waters, thickness of surface layer, jet distance to thermocline, velocity of jet, temperature difference between jet and bottom waters

measured nitrate concentration in sewage, comparison of three different methods

efficiency of solar space-heating system, a computer simulation

extent of corrosion of iron

measurement of butterfat content of milk

time to complete job on computer

two different measures of efficiency of operation of gas chromatograph

measured cortisol level in human blool plasma

extent of rock candy fracture of cast steel

measurement of angle with photogrammetric instrument

changes in height, width, and length dimensions of cast metal

quality of weld made by submerged arc welding process

recover of material by steam distillation

final moisture content of alfalfa protein

odor produced by material isolated from decaying manure, after treatment

limiting currents on totaling disk electrode

measured temperature of a heated plate

sensitivity of microdensitometer

efficiency of vacuum filtration of sludge

longitudinal and thrust forces for surface grinding operation

chemical oxygen demand of samples with same amount of waste (acetanilide)

torque of taper roller bearings

adsorption characteristics of activated carbon used with municipal waste water

impact strength of steel alloy

percentage of panelists correctly identifying which samples were lamb

methane concentration in completed sanitary landfill

electrocardiogram reading

removal of turbidity and hardness from water

mixing time for an initially thermally stratified tank of water 